\title{
To Evaluate and Explain the Consequences of Abnormal Anal Sphincter Morphology Using the 3-Dimensional Endosonography
}

\author{
Ashraf Talaat Youssef \\ Department of Radiology, Faculty of Medicine, Fayoum University, Fayoum 63511, Egypt \\ Correspondence should be addressed to Ashraf Talaat Youssef; ashraftalaat1@yahoo.com
}

Received 8 July 2014; Accepted 30 October 2014; Published 20 November 2014

Academic Editor: Sergio Casciaro

Copyright (C) 2014 Ashraf Talaat Youssef. This is an open access article distributed under the Creative Commons Attribution License, which permits unrestricted use, distribution, and reproduction in any medium, provided the original work is properly cited.

\begin{abstract}
The Objective of the Study. To evaluate and explain the consequences of different morphological abnormalities of anal sphincters including the sphincter damage and its extent using the 3-dimensional endosonography. Material and Methods. 56 patients suffering from fecal incontinence all were subjected to analysis of patient symptoms, scoring the severity of symptoms, digital examination, electromyography, and 3D endoanal ultrasonography. Results. 5 patients showed intact anal sphincters and puborectalis muscle. 4 patients found with thick IAS $>4 \mathrm{~mm}, 4$ patients with thin IAS $<2 \mathrm{~mm} .3$ patients with thin EAS, 12 patients with IAS defects, 15 patients with EAS defects, 8 patients with combined IAS and EAS defects, 2 patients with puborectalis muscle defects and 3 patients with high levels transsphincteric perianal fistulas. Conclusion. No significant relationship was observed between sphincter damage except for combined internal and external sphincter injury and the severity score of FI symptoms. Puborectalis muscle injury and abnormal sphincter thickness are unlikely causes of severe FI.
\end{abstract}

\section{Introduction}

Anal continence recommends the integrity of all parts of anorectal region. When the rectum distends with fecal matter stretch receptors in its walls, send rectoanal inhibitory reflex which relax the internal anal sphincter (IAS) and contract the external anal sphincter (EAS). When the surroundings are suitable defecation proceeding with rising of intra-abdominal pressure, relaxation of the puborectalis muscle with subsequent increase of the anorectal angle and relaxation of external anal sphincter to get rid of fecal matter, but when the surroundings are unsuitable voluntary contraction of external anal sphincter and puborectalis muscle leads to inhibition of rectoanal inhibitory reflex, relaxation of rectal wall muscles and subsequent backward colonic peristalsis force the fecal matter to return back to the colon [1].

Two-dimensional (2D) transrectal ultrasound (TRUS) was used to assess the presence of sphincter damage with high sensitivity and specificity $[2,3]$.

Three-dimensional (3D) endoanal ultrasound helps to assess accurately the extent of anal sphincter damage in
3 perpendicular planes (axial, coronal, and sagittal). The coronal plane is the blind plane for 2D ultrasound [4-6].

Obstetric trauma may contribute to fecal incontinence (FI) through sphincter damage, perineal descent, and pudendal nerve injury [7-11]. Internal and/or external sphincter damage is major causes of posttraumatic fecal incontinence $[12,13]$. Previous studies showed that the extent of sphincter damage correlated with the severity of fecal incontinence $[14,15]$ what was opposed by other studies which showed that many patients with sphincter defects had no manifestations of fecal incontinence [16] and no correlation was found between the extent of sphincter damage and the severity of fecal incontinence [9-11, 17, 18].

\section{The Aim of the Work}

Based on the significant role of anal sphincters and puborectalis muscle in preserving anal continence, the current study aimed to evaluate and explain the consequences of different morphological abnormalities of anal sphincters including the 
sphincter damage and its extent using the 3-dimensional endosonography.

\section{Methodology}

Referred 56 patients suffered from fecal incontinence to the radiology department of my institution following an obstetric trauma (20 patients), anorectal surgery (14 patients), anal dilation (3 patients), traffic accidents (3 patients), complex perianal fistula (3 patients), and unknown etiology (13 patients); the mean age was 35 years (range 20 to 70 years), they were 34 females and 22 males, and all were subject to the following.

Analysis of patient symptoms and scoring the severity of symptoms using a bowel function questionnaire modified from Jorge and Wexner and the score (0-20) assesses the presence of incontinence to flatus, fecal soiling, frank fecal incontinence, fecal urgency, and impact on daily activities. In each of the 5 categories, patients were asked to record a score of $0-4$, with 0 representing no problem and 4 a severe problem. The scores from each category were added and a continence score (CS) was given, score of 1-4 denotes mild symptoms, a score of 5-9 denotes moderate symptoms, and a score $>9$ denotes severe symptoms [19].

3.1. Digital Rectal Examination. For electromyography (EMG) in which the electrical activity of external anal sphincter was measured during rest and squeeze in cases with suspected damage using concentric needle electrode, the electrode was inserted directly into the EAS guided with a needle and measurements were taken and interpreted from multiple sites (sphincter mapping) by experienced electromyographer at private center. Ultrasound exam was performed first and then correlated with the report of EMG comparing the sites of EAS damage by ultrasound and the sites of absent electrical activity in EMG report.

3D endoanal ultrasonography by experienced operator using 3D endoanal high frequency mechanical probe, Voluson 530D ultrasonography machine (Kretz technique, Austria): the patients were examined in left lateral decubitus position. The endoanal ultrasound probe was inserted into the anal canal. The 2-dimensional (2D) ultrasound exam was performed first taking multiple sequential axial scans to the whole circumference of anal canal from low to high canal levels followed by $3 \mathrm{D}$ volume scan to the region of interest and the suspected sphincter defect. Data were stored and analyzed in multiplanar image analysis and volume rendering.

The extent of sphincter defect was estimated in the 3 perpendicular planes and the thickness of internal and external anal sphincters was measured at 3 and 9 oclock at midanal canal level.

Internal anal sphincter was seen as a band of hypoechogenicity of uniform thickness (2-3 mm) [20, 21]. External anal sphincter showed moderate echogenicity and thickness ranging from 10 to $12 \mathrm{~mm}$ [22].

An additional transvaginal $3 \mathrm{D}$ ultrasound examination using an endovaginal multifrequency probe ( 5 to $7 \mathrm{MHz}$ ) for female patients and transperineal ultrasound exam using a
TABLE 1: Endoanal ultrasound findings and the number of cases.

\begin{tabular}{lcc}
\hline Endoanal 3D ultrasound findings & $N$ & $\%$ \\
\hline IAS defect & 12 & 21.4 \\
EAS defect & 15 & 26.8 \\
Combined IAS and EAS defects & 8 & 14.2 \\
Thick IAS & 4 & 7.1 \\
Thin IAS & 4 & 7.1 \\
Thin EAS & 3 & 5.3 \\
Puborectalis muscle injury & 2 & 3.5 \\
Transsphincteric fistula & 3 & 5.3 \\
Normal ultrasound & 5 & 8.9 \\
\hline Total & 56 & 100.0 \\
\hline
\end{tabular}

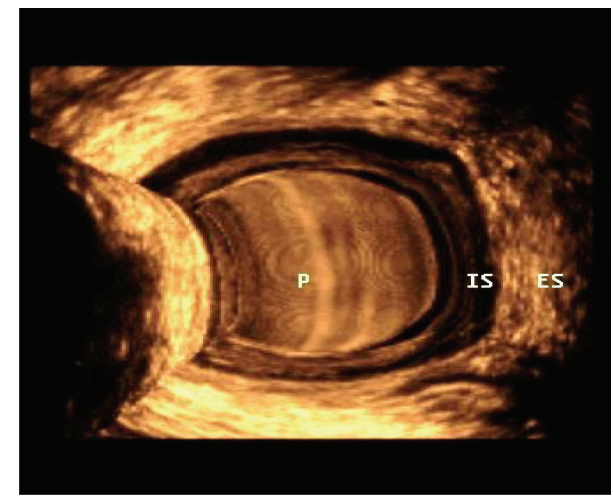

FIgURE 1: Normal 3D-TRUS of anal canal at midcanal level. Probe (p), internal sphincter (IS), and external sphincter (ES).

high frequency linear probe for all patients were performed for better assessment of the lesion.

The extent of isolated internal and/or external sphincter defects was compared with the surgical results and was correlated with the severity score of FI symptoms.

3.2. Statistical Analysis of Data. The collected data were organized, tabulated, and statistically analyzed using SPSS software statistical computer package version 19 (SPSS Inc., USA). The data were represented as number and percent; chi square $\left(\chi^{2}\right)$ test was used as a test of significance. For interpretation of results of tests of significance, significance was adopted at $P<0.05$

\section{Results}

56 patients with FI were examined (Table 1), 5 patients showed intact anal sphincters and puborectalis muscle (Figures 1, 2, and 3), and 4 patients were found with thick IAS $>4 \mathrm{~mm}$ (Figure 4 ) and 4 patients with thin IAS $<2 \mathrm{~mm}$. Three patients with thin EAS, 12 patients showed IAS defects (Figures 5 and 11), 15 patients detected with EAS defects (Figures 6, 7, 8, and 9), 8 patients with combined IAS and EAS defects (Figure 10), 2 patients with puborectalis muscle defects and 3 patients found with high levels transsphincteric perianal fistulas. 

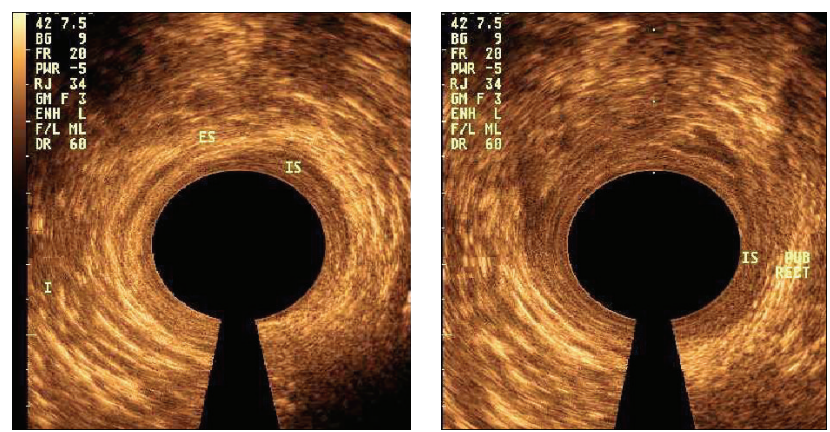

Figure 2: Normal 2D ultrasound of anal canal at mid- and high anal canal levels.

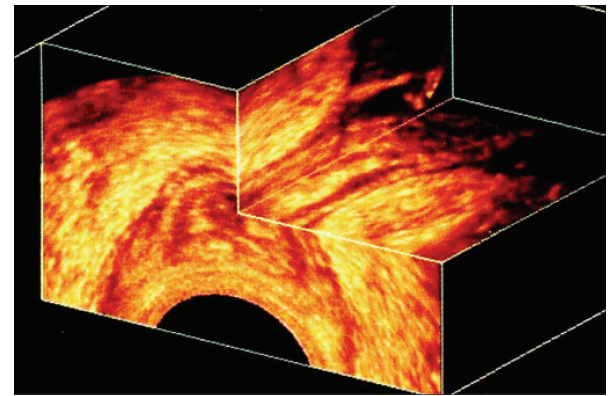

FIGURE 3: 3D niche mode showing the whole length of the anal canal and the rectum.

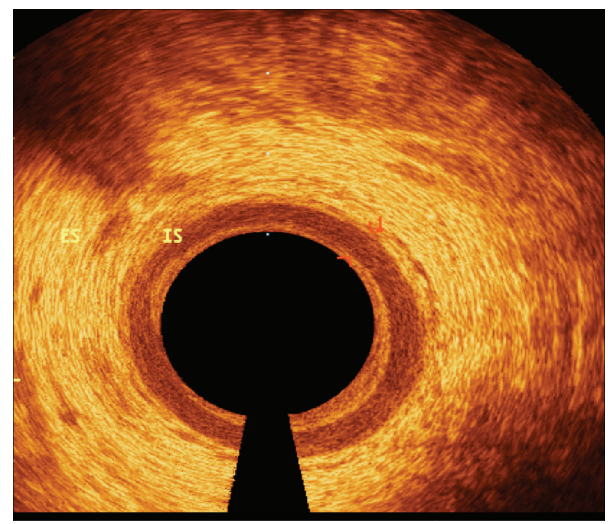

FIGURE 4:2D TRUS showing abnormal diffuse thickening of internal anal sphincter (IS) with normal external anal sphincter (ES).

11 of 15 patients with external sphincter defects and 6 of 8 patients with combined external and internal sphincter defects that have undergone surgery and contact with the surgeons after surgery for the operative results revealed an excellent correlation between the operative findings and 3D ultrasonography, with respect to the site, the shape, and extent of the defects except for 1 case with an external sphincter defect in whom the size of the defect was underestimated and one case diagnosed as combined EAS and IAS defect and proved at surgery as an isolated EAS defect.

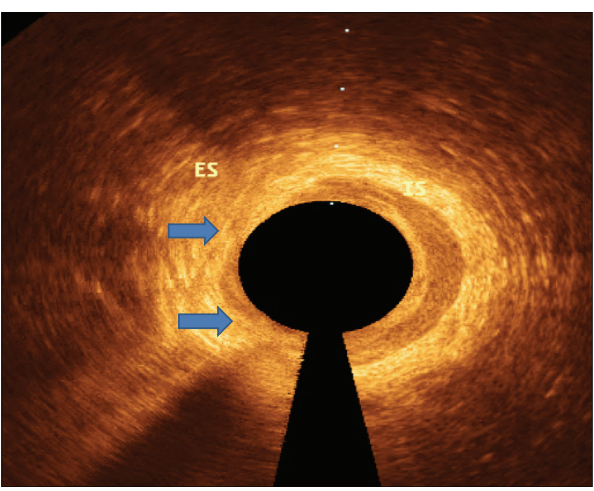

FIGURE 5: 2D TRUS showing unilateral full thickness, internal sphincter defect (arrows) involving half of its circumference.
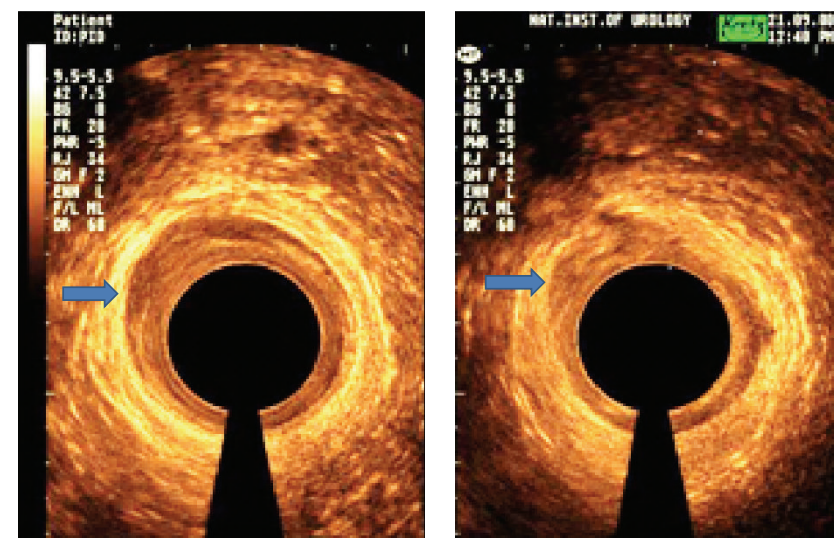

FIGURE 6: 2D TRUS showing partial thickness external sphincter defect (arrow) involving $<25 \%$ of anal canal circumference.
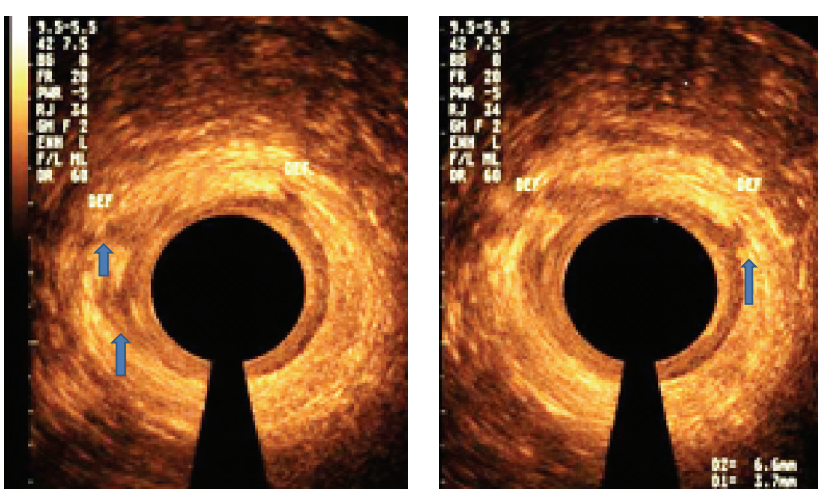

FIGURE 7:2D TRUS showing multiple external anal sphincter defects (arrows).

There was complete agreement between the site of external sphincter defect and the EMG mapping results in loss of electrical activity at sites of the defects.

No significant relationship was observed between the extent of internal sphincter defects and the severity score 


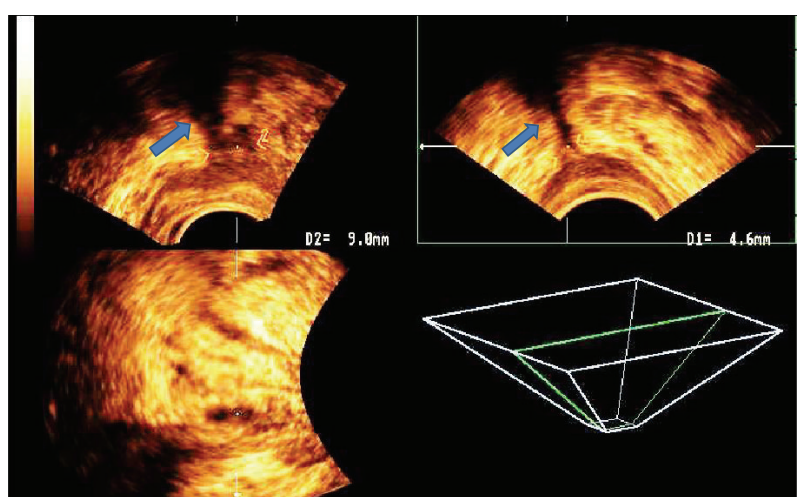

FIGURE 8: 3D TRUS with multiplanar image analysis showing the extent of external anal sphincter defect (arrow) in 3 perpendicular planes.

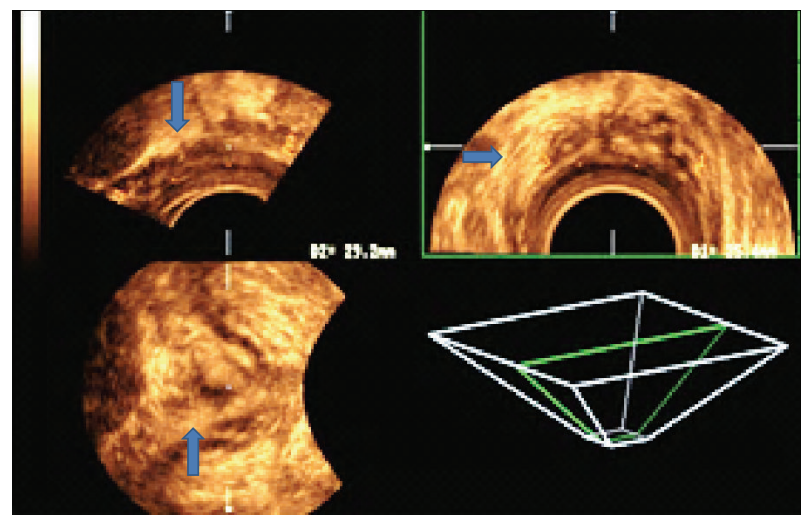

FIGURE 9: 3D TRUS with multiplanar image analysis showing the extent of anterior external anal sphincter damage (arrows).

TABLE 2: Extent of internal anal sphincter defects, the number of cases, and the severity of symptoms.

\begin{tabular}{lcccccc}
\hline \multirow{2}{*}{ IAS defects } & \multicolumn{2}{c}{ Severity of FI symptoms } & \multicolumn{2}{c}{ Total } \\
& $N$ & $\%$ & $N$ & $\%$ & $N$ & $\%$ \\
\hline Fragmentation & 3 & 100.0 & 0 & 0.0 & 3 & 100.0 \\
IAS defect $<25 \%$ & 3 & 50.0 & 3 & 50.0 & 6 & 100.0 \\
IAS defect $>25 \%$ & 3 & 100.0 & 0 & 0.0 & 3 & 100.0 \\
\hline Total & 9 & 75.0 & 3 & 25.0 & 12 & 100.0 \\
\hline$\chi^{2}=4.00 ; P$ value $=0.135$ (>0.05-nonsignificant). & & &
\end{tabular}

of FI symptoms (Table 2) as $P$ value $=0.135(>0.05-$ nonsignificant) or between the extent of the external sphincter defects and the severity score of FI symptoms (Table 3 ) as $P$ value $=0.242$ ( $>0.05$-nonsignificant $)$.

A significant relationship was observed between combined IAS and EAS defects and the severity score of FI symptoms (Table 4$)$ as $P$ value $=0.010(<0.05-$ significant $)$.

A significant relationship was found between the anterior external sphincter injury in females and the severity of fecal incontinence as $P$ value $=0.020(<0.05$ - significant $)$.

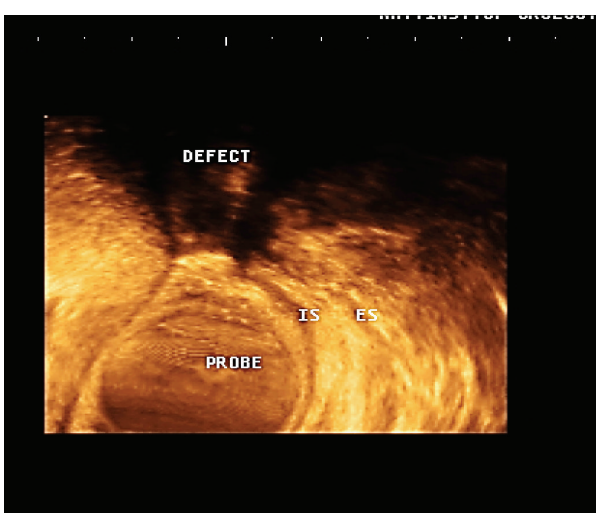

FIGURE 10: 3D TRUS volume rendering of combined external and internal sphincter defect. Internal sphincter (IS), external sphincter (ES).

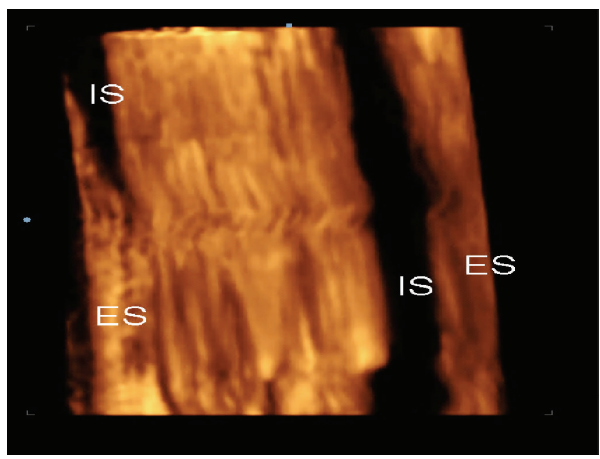

FIGURE 11: 3D surface rendering with sagittal reconstruction of anal canal showing unilateral loss of internal anal sphincter at the lower half of the anal canal. Internal sphincter (IS), external sphincter (ES).

No significant relationship was observed between the thickness of IAS or EAS and the severity score of FI symptoms (Table 5) as $P$ value $=0.307$ ( $>0.05$-nonsignificant) .

\section{Discussion}

Internal anal sphincter is responsible for $70-80 \%$ of the resting anal pressure [23] and in the more recent study, $55 \%$ [24], so it was expected that its damage leads to fecal incontinence at rest. Shafik [25] showed that the harm to the IAS leads to stress defecation. Also other studies emphasized the important purpose of IAS in maintaining fecal continence at rest $[12,26]$. The current study showed that fragmentation and large IAS defects were associated with only mild FI. Nielsen et al. [27] demonstrated that serious damage to IAS after anal dilatation did not lead to fecal incontinence. Lateral sphincterotomy only leads to $1.3 \%$ incidence of FI and complete division of IAS may lead to FI in up to $30 \%$ of cases [28, 29]. Petros and Anderson [30] found that isolated variable size IAS defect in a group of 18 patients was minimally associated with FI.

So in spite of the fact that IAS is important in maintaining fecal continence, its damage leads to mild FI if any! That can be explained as the external anal sphincter can change 
TABLE 3: Extent of external sphincter defects, the number of cases, and the severity of symptoms.

\begin{tabular}{|c|c|c|c|c|c|c|c|c|}
\hline \multirow{3}{*}{ External } & \multicolumn{6}{|c|}{ Severity of FI symptoms } & \multirow{2}{*}{\multicolumn{2}{|c|}{ Total }} \\
\hline & \multicolumn{2}{|c|}{ Mild } & \multicolumn{2}{|c|}{ Moderate } & \multicolumn{2}{|c|}{ Severe } & & \\
\hline & $N$ & $\%$ & $N$ & $\%$ & $N$ & $\%$ & $N$ & $\%$ \\
\hline Full thickness tears & 5 & 71.4 & 2 & 28.6 & 0 & 0.0 & 7 & 100.0 \\
\hline Partial thickness defect $<25 \%$ & 1 & 25.0 & 1 & 25.0 & 2 & 50.0 & 4 & 100.0 \\
\hline Partial thickness defect $>25 \%$ & 3 & 75.0 & 0 & 0.0 & 1 & 25.0 & 4 & 100.0 \\
\hline Total & 9 & 60.0 & 3 & 20.0 & 3 & 20.0 & 15 & 100.0 \\
\hline
\end{tabular}

$\chi^{2}=5.48 ; P$ value $=0.242$ (>0.05-nonsignificant).

TABLE 4: Relationship between isolated or combined sphincteric defects and the severity of FI symptoms.

\begin{tabular}{|c|c|c|c|c|c|c|c|c|}
\hline \multirow{3}{*}{ Sphincter defects } & \multicolumn{6}{|c|}{ Severity of FI symptoms } & & \\
\hline & \multicolumn{2}{|c|}{ Mild } & \multicolumn{2}{|c|}{ Moderate } & \multicolumn{2}{|c|}{ Severe } & \multicolumn{2}{|c|}{ Total } \\
\hline & $N$ & $\%$ & $N$ & $\%$ & $N$ & $\%$ & $N$ & $\%$ \\
\hline IAS only & 9 & 75.0 & 0 & 0.0 & 3 & 25.0 & 12 & 100.0 \\
\hline EAS only & 9 & 60.0 & 3 & 20.0 & 3 & 20.0 & 15 & 100.0 \\
\hline Combined IAS and EAS & 0 & 0.0 & 2 & 25.0 & 6 & 75.0 & 8 & 100.0 \\
\hline Total & 18 & 51.4 & 5 & 14.3 & 12 & 34.3 & 35 & 100.0 \\
\hline
\end{tabular}

$\chi^{2}=13.4 ; P$ value $=0.010(<0.05$-significant $)$.

TABLE 5: Other findings rather than EAS and IAS defects by TRUS, the number of cases, and the severity of symptoms.

\begin{tabular}{lcccccc}
\hline \multirow{2}{*}{ Other findings } & \multicolumn{3}{c}{ Severity of FI symptoms } \\
& $N$ & $\%$ & $N$ & $\%$ & $N$ & $\%$ \\
\hline Thin IAS & 4 & 100.0 & 0 & 0.0 & 4 & 100.0 \\
Thick IAS & 4 & 100.0 & 0 & 0.0 & 4 & 100.0 \\
Thin EAS & 2 & 66.7 & 1 & 33.3 & 3 & 100.0 \\
Puborectalis muscle injury & 2 & 100.0 & 0 & 0.0 & 2 & 100.0 \\
\hline Total & 12 & 92.3 & 1 & 7.7 & 13 & 100.0 \\
\hline$\chi^{2}=3.61 ; P$ value $=0.307(>0.05-$ nonsignificant $)$. & & &
\end{tabular}

its state of tone at rest and it is responsible for $15-20 \%$ of the resting anal pressure, which can increase to $40 \%$ during rectal distension with augmented function indicating the presence of dynamic rectoanal response [23,31]. Voyvodic et al. [17] reported that full thickness external sphincter tear was associated with a significant reduction in the resting anal pressure, which is mainly preserved with IAS; also internal anal sphincter damage was associated with an increase in the electromyographic activity of external anal sphincter. This runs to a suggestion about a compensatory mechanism by the external anal sphincter during IAS damage. Barrett et al. [32] and Farouk et al. [33] demonstrated that damage to IAS can be compensated by the healthy external anal sphincter and puborectalis muscle, and weakness for either of these muscles in association with IAS damage makes FI manifest.

The current study showed that large isolated external anal sphincter tear may lead to only mild FI. That can be explained as Shafik [25] reported that external anal sphincter was formed of 3 loops, each of them acts as a single sphincter and puborctalis muscle shares in the formation of upper loop, based on anatomical and physiological study. An injury to a single loop can be made up by the other loops to maintain voluntary continence, so to impair voluntary continence there should be an extensive injury to all three loops including the puborectalis muscle. Also 3-dimensional magnetic resonance imaging study of nulliparous women identified 3 separate portions of EAS with different fiber direction, suggesting a different biomechanical function of each portion [34].

In malice of the significant role of puborectalis muscle in creating the anorectal angle during rest and squeeze and in preserving fecal continence $[35,36]$, the current survey showed only mild minor incontinence observed in 2 cases of puborectalis injury. Also Chantarasorn et al. [37] reported that avulsion of puborectalis muscle may not lead to FI and Petros and Swash [38] revealed that it receives just mild symptoms. These findings suggest a compensatory mechanism by the external anal sphincter during squeeze which is able to create water and gas tight continence [25], shared with the compensation offered by the IAS to maintain continence at rest.

5.1. The Following to Be Considered. The high prevalence of associated nerve damage and sphincter defects in cases of FI after delivery [39]. The high prevalence of FI in cases with combined internal and external anal sphincter injury [40] matches with the current study. The association between motor nerve damage to the puborectalis muscle and pudendal nerve damage to the external anal sphincter among patients with idiopathic FI [39]. The association between reduced rectal compliance and diminished IAS tone is in another group of the idiopathic FI [41]. Also the efficacy of sphincter 
repair is reduced to only $10 \%$ if associated nerve damage was present [40].

All the aforementioned findings suggest that more than single factor is responsible for FI and the isolated sphincter injury cannot be responsible alone for manifested FI. Other etiological factors like associating nerve damage, old age, abnormal sphincteric thickness as thin internal sphincter in cases of anal hypertone, or thick internal sphincter observed with old age or with obstructed defecation, injury to the puborectalis muscle and combined sphincter injury should be looking for before an attempt of surgical repair.

Old age is regarded as a factor as with increasing age IAS thickness and EAS becomes thinner and weak [21]. Sex is probably a factor as EAS is larger in males than in females regarding the muscle bulk and length; likewise the maximum squeeze pressure in females is significantly lower than males [42]. That implies that old female in the presence of sphincter damage is more liable to manifest FI than an old male.

5.2. Limitations of the Study. The number of cases with abnormal sphincter thickness and with puborectalis muscle injuries should be increased to be correlated with the severity of FI.

Rectal sensation and stool consistency are two factors that influence the fecal continence and were not considered as an associated factor that can change the severity of FI in patients with abnormal sphincter morphology.

When assessing the severity of fecal incontinence data about the influence of FI on the patient quality of life were not sufficiently supplied and are recommended in further studies.

During evaluation of patients with perianal fistulas, the concomitant painful abscess might have presented an obstacle to an efficient muscle contraction.

\section{Conclusion}

No significant relationship was observed between sphincter damage except for combined internal and external sphincter injury, an injury to the anterior aspect of external sphincter in females, and the severity score of FI symptoms. Puborectalis muscle injury and abnormal sphincter thickness are unlikely causes of severe FI.

\section{Disclosure}

The paper is not under publication or revision by any other journals.

\section{Conflict of Interests}

The author declares that there is no conflict of interests regarding the publication of this paper.

\section{Author's Contribution}

Ashraf Talaat Youssef has contributed to conception and design of the study, collection, analysis and interpretation of data, and drafting the paper with final approval of its completed form.

\section{References}

[1] S. S. C. Rao, "Pathophysiology of adult fecal incontinence," Gastroenterology, vol. 126, supplement 1, no. 1, pp. S14-S22, 2004.

[2] R. Thakar and A. H. Sultan, "Anal endosonography and its role in assessing the incontinent patient," Best Practice and Research: Clinical Obstetrics and Gynaecology, vol. 18, no. 1, pp. 157-173, 2004.

[3] D. L. Faltin, M. Boulvain, L. A. Floris, and O. Irion, "Diagnosis of anal sphincter tears to prevent fecal incontinence: a randomized controlled trial," Obstetrics \& Gynecology, vol. 106, no. 1, pp. 6-13, 2005.

[4] I. P. Olsen, K. Augensen, T. Wilsgaard, and T. Kiserud, "Three-dimensional endoanal ultrasound assessment of the anal sphincters: reproducibility," Acta Obstetricia et Gynecologica Scandinavica, vol. 87, no. 6, pp. 675-681, 2008.

[5] I. P. Olsen, K. Augensen, T. Wilsgaard, and T. Kiserud, "Three-dimensional endoanal ultrasound assessment of the anal sphincters during rest and squeeze," Acta Obstetricia et Gynecologica Scandinavica, vol. 87, no. 6, pp. 669-674, 2008.

[6] G. Gravante and P. Giordano, "The role of three-dimensional endoluminal ultrasound imaging in the evaluation of anorectal diseases: a review," Surgical Endoscopy and Other Interventional Techniques, vol. 22, no. 7, pp. 1570-1578, 2008.

[7] S. Karoui, C. Savoye-Collet, E. Koning, A.-M. Leroi, and P. Denis, "Prevalence of anal sphincter defects revealed by sonography in 335 incontinent patients and 115 continent patients," American Journal of Roentgenology, vol. 173, no. 2, pp. 389-392, 1999.

[8] L. Abramowitz, I. Sobhani, R. Ganansia et al., "Are sphincter defects the cause of anal incontinence after vaginal delivery? Results of a prospective study," Diseases of the Colon and Rectum, vol. 43, no. 5, pp. 590-598, 2000.

[9] T. Tetzschner, M. Sorensen, G. Lose, and J. Christiansen, "Anal and urinary incontinence in women with obstetric anal sphincter rupture," British Journal of Obstetrics and Gynaecology, vol. 103, no. 10, pp. 1034-1040, 1996.

[10] M. B. Nielsen, C. Hauge, J. F. Pedersen, and J. Christiansen, "Endosonographic evaluation of patients with anal incontinence: findings and influence on surgical management," American Journal of Roentgenology, vol. 160, no. 4, pp. 771-775, 1993.

[11] M. Sorensen, T. Tetzschner, O. O. Rasmussen, J. Bjarnesen, and J. Christiansen, "Sphincter rupture in childbirth," British Journal of Surgery, vol. 80, no. 3, pp. 392-394, 1993.

[12] S. J. D. Burnett, C. Spence-Jones, C. T. M. Speakman, M. A. Kamm, C. N. Hudson, and C. I. Bartram, "Unsuspected sphincter damage following childbirth revealed by anal endosonography," British Journal of Radiology, vol. 64, no. 759, pp. 225-227, 1991.

[13] M. Barthet, P. Bellon, E. Abou et al., "Anal endosonography for assessment of anal incontinence with a linear probe: relationships with clinical and manometric features," International Journal of Colorectal Disease, vol. 17, no. 2, pp. 123-128, 2002.

[14] S. Norderval, A. Markskog, K. Røssaak, and B. Vonen, "Correlation between anal sphincter defects and anal incontinence following obstetric sphincter tears: assessment using scoring systems for sonographic classification of defects," Ultrasound in Obstetrics \& Gynecology, vol. 31, no. 1, pp. 78-84, 2008. 
[15] C. Vaccaro and J. L. Clemons, "Anal sphincter defects and anal incontinence symptoms after repair of obstetric anal sphincter lacerations in primiparous women," International Urogynecology Journal and Pelvic Floor Dysfunction, vol. 19, no. 11, pp. 15031508, 2008.

[16] P. M. Falk, G. J. Blatchford, R. L. Cali, M. A. Christensen, and A. G. Thorson, "Transanal ultrasound and manometry in the evaluation of fecal incontinence," Diseases of the Colon and Rectum, vol. 37, no. 5, pp. 468-472, 1994.

[17] F. Voyvodic, N. A. Rieger, S. Skinner et al., "Endosonographic imaging of anal sphincter injury: does the size of the tear correlate with the degree of dysfunction?" Diseases of the Colon and Rectum, vol. 46, no. 6, pp. 735-741, 2003.

[18] N. Wasserberg, A. Mazaheri, P. Petrone, H. Tulchinsky, and H. S. Kaufman, "Three-dimensional endoanal ultrasonography of external anal sphincter defects in patients with faecal incontinence: correlation with symptoms and manometry," Colorectal Disease, vol. 13, no. 4, pp. 449-453, 2011.

[19] J. M. N. Jorge and S. D. Wexner, "Etiology and management of fecal incontinence," Diseases of the Colon \& Rectum, vol. 36, no. 1, pp. 77-97, 1993.

[20] J. Stoker, S. Halligan, and C. I. Bartram, "Pelvic floor imaging," Radiology, vol. 218, no. 3, pp. 621-641, 2001.

[21] A. Frudinger, S. Halligan, C. I. Bartram, A. B. Price, M. A. Kamm, and R. Winter, "Female anal sphincter: age-related differences in asymptomatic volunteers with high-frequency endoanal US," Radiology, vol. 224, no. 2, pp. 417-423, 2002.

[22] P. J. Law, M. A. Kamm, and C. I. Bartram, "Anal endosonography in the investigation of faecal incontinence," British Journal of Surgery, vol. 78, no. 3, pp. 312-314, 1991.

[23] B. Frenckner and C. V. Euler, "Influence of pudendal block on the function of the anal sphincters," Gut, vol. 16, no. 6, pp. 482489, 1975.

[24] B. Lestar, F. Penninckx, and R. Kerremans, "The composition of anal basal pressure. An in vivo and in vitro study in man," International Journal of Colorectal Disease, vol. 4, no. 2, pp. 118$122,1989$.

[25] A. Shafik, "A new concept of the anatomy of the anal sphincter mechanism and the physiology of defecation. IX. Single loop continence: a new theory of the mechanism of anal continence," Diseases of the Colon and Rectum, vol. 23, no. 1, pp. 37-43, 1980.

[26] R. Mahony, M. Behan, L. Daly, C. Kirwan, C. O'Herlihy, and P. R. O'Connell, "Internal anal sphincter defect influences continence outcome following obstetric anal sphincter injury," American Journal of Obstetrics and Gynecology, vol. 196, no. 3, pp. 217.el-217.e5, 2007.

[27] M. B. Nielsen, O. Ø. Rasmussen, J. F. Pedersen, and J. Christiansen, "Risk of sphincter damage and anal incontinence after anal dilatation for fissure-in-ano: an endosonographic study," Diseases of the Colon \& Rectum, vol. 36, no. 7, pp. 677-680, 1993.

[28] F. Cadeddu, I. Selvaggio, M. Muzi, F. Andreoli, D. Amabile, and G. Milito, "Complications and results of lateral internal sphincterotomy for chronic anal fissure," BMC Geriatrics, vol. 9, supplement 1, article A91, 2009.

[29] A. H. Sultan, M. A. Kamm, R. J. Nicholls, and C. I. Bartram, "Prospective study of the extent of internal anal sphincter division during lateral sphincterotomy," Diseases of the Colon and Rectum, vol. 37, no. 10, pp. 1031-1033, 1994.

[30] P. E. P. Petros and J. Anderson, "Role of internal anal sphincter damage in the causation of idiopathic faecal incontinence: a prospective study," Australian and New Zealand Journal of Obstetrics and Gynaecology, vol. 45, no. 1, pp. 77-78, 2005.
[31] A. Bajwa, K. Thiruppathy, P. Trivedi, P. Boulos, and A. Emmanuel, "Effect of rectal distension on voluntary external anal sphincter function in healthy subjects," Colorectal Disease, vol. 13, no. 10, pp. 1173-1179, 2011.

[32] J. A. Barrett, J. C. Brocklehurst, E. S. Kiff, G. Ferguson, and E. B. Faragher, "Anal function in geriatric patients with faecal incontinence," Gut, vol. 30, no. 9, pp. 1244-1251, 1989.

[33] R. Farouk, G. S. Duthie, A. Pryde, A. B. McGregor, and D. C. C. Bartolo, "Internal anal sphincter dysfunction in neurogenic faecal incontinence," British Journal of Surgery, vol. 80, no. 2, pp. 259-261, 1993.

[34] Y. Hsu, D. E. Fenner, W. J. Weadock, and J. O. L. DeLancey, "Magnetic resonance imaging and 3-dimensional analysis of external anal sphincter anatomy," Obstetrics and Gynecology, vol. 106, no. 6, pp. 1259-1265, 2005.

[35] K. K. Varma and D. Stephens, "Neuromuscular reflexes of rectal continence.," Australian and New Zealand Journal of Surgery, vol. 41, no. 3, pp. 263-272, 1972.

[36] P. R. Barnes, P. R. Hawley, D. M. Preston, and J. E. LennardJones, "Experience of posterior division of the puborectalis muscle in the management of chronic constipation," British Journal of Surgery, vol. 72, no. 6, pp. 475-477, 1985.

[37] V. Chantarasorn, K. L. Shek, and H. P. Dietz, "Levator avulsion is not associated with fecal incontinence," International Urogynecology Journal, vol. 20, supplement 2, pp. S169-S170, 2009.

[38] P. Petros and M. Swash, "Study no. 7: role of puborectalis muscle in anal continence. Comments on original $4 \mathrm{D}$ pelvic ultrasound data from Chantarasorn \& Dietz," Diseases of the Colon \& Rectum, vol. 36, no. 7, pp. 677-668, 1993.

[39] S. J. Snooks, M. Swash, S. E. Mathers, and M. M. Henry, "Effect of vaginal delivery on the pelvic floor: a 5-year follow-up," British Journal of Surgery, vol. 77, no. 12, pp. 1358-1360, 1990.

[40] S. Laurberg, M. Swash, and M. M. Henry, "Delayed external sphincter repair for obstetric tear," British Journal of Surgery, vol. 75, no. 8, pp. 786-788, 1988.

[41] N. R. Womack, J. F. B. Morrison, and N. S. Williams, "The role of pelvic floor denervation in the aetiology of idiopathic faecal incontinence," British Journal of Surgery, vol. 73, no. 5, pp. 404407, 1986.

[42] R. J. F. Felt-Bersma, G. Gort, and S. G. M. Meuwissen, "Normal values in anal manometry and rectal sensation: a problem of range," Hepato-Gastroenterology, vol. 38, no. 5, pp. 444-449, 1991. 


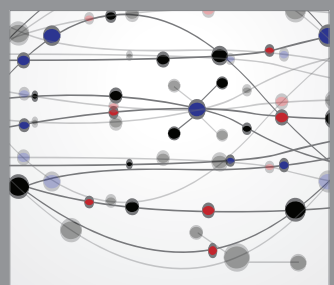

The Scientific World Journal
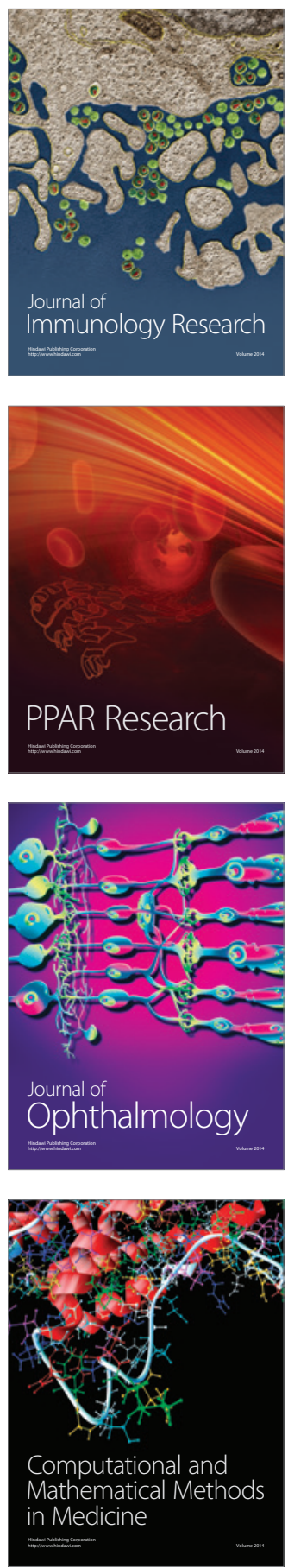

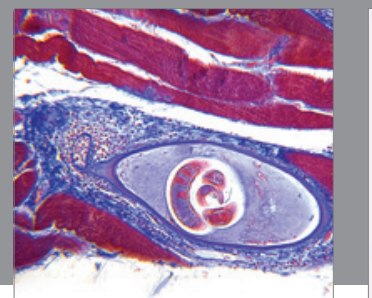

Gastroenterology

Research and Practice
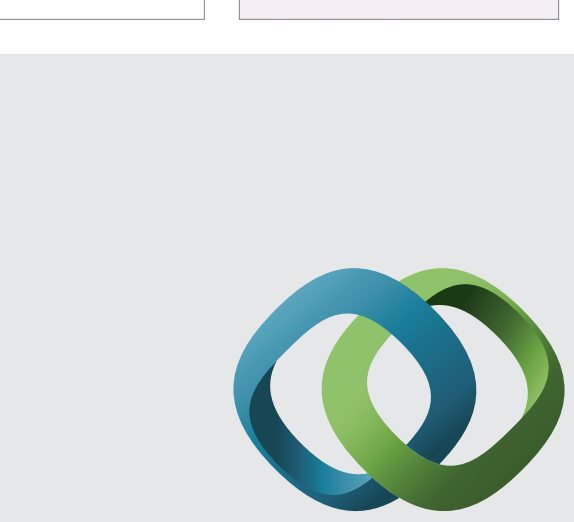

\section{Hindawi}

Submit your manuscripts at

http://www.hindawi.com
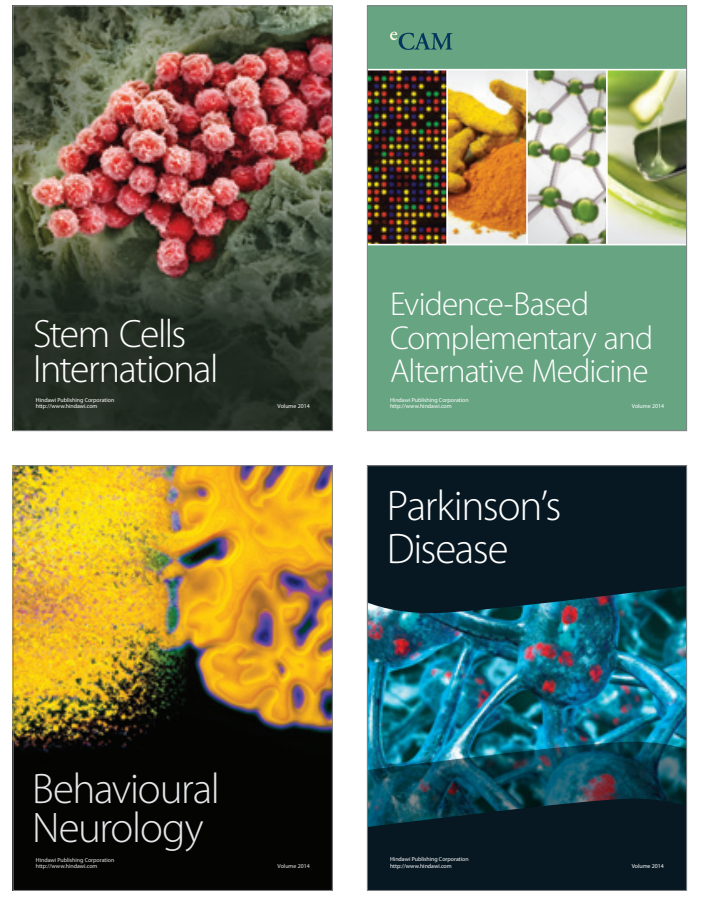
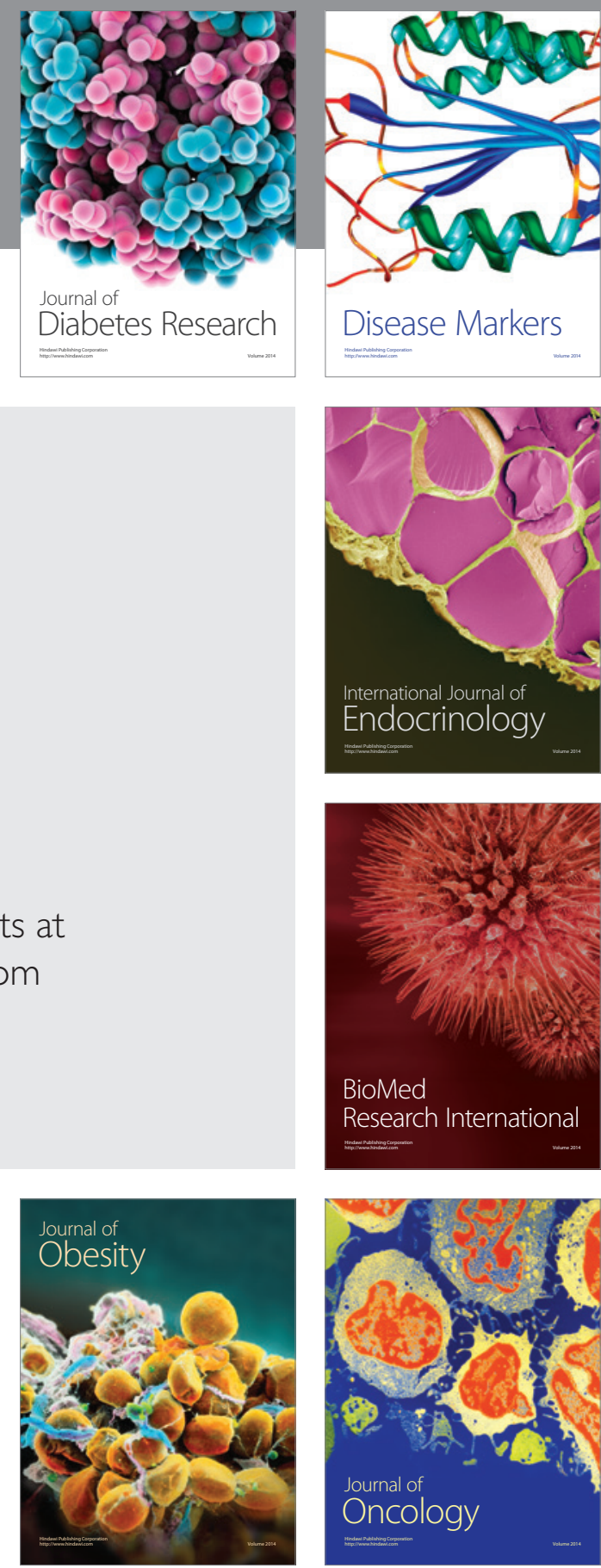

Disease Markers
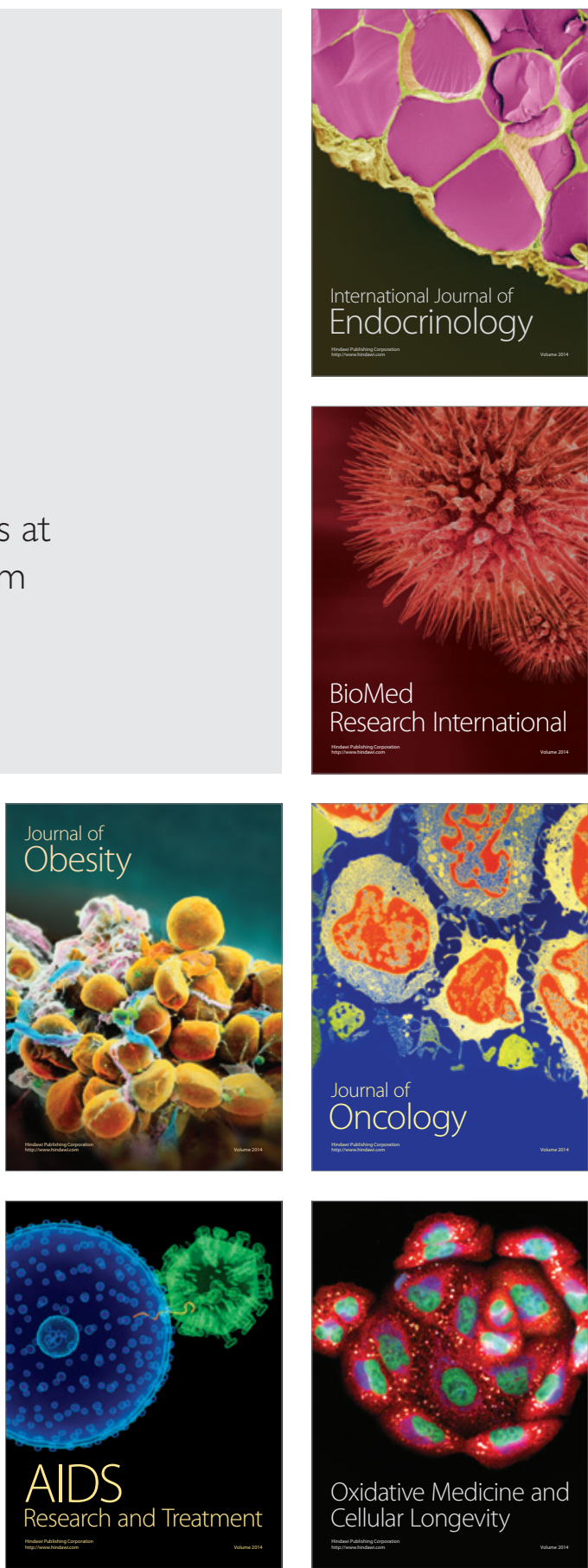